\title{
Double jeopardy: Failure to deflate stent balloon in rescue angioplasty
}

\author{
RUTVIK TRIVEDI* \\ Department of Cardiology, Zydus Hospital and Research Centre, Anand, India \\ ${ }^{*}$ Corresponding address: Dr. Rutvik Trivedi, MD, DM (Cardiology), Consultant Cardiologist; Department of Cardiology, Zydus Hospital and \\ Research Centre, Anand-Lambhvel Road, Anand 388001, Gujarat, India; Phone: +91 98256 14079; Fax: +91 2692619517 ; \\ E-mail: i_me_myself78@yahoo.com
}

(Received: May 16, 2018; Revised manuscript received: March 11, 2019; Accepted: May 12, 2019)

\begin{abstract}
Failure to deflate the angioplasty balloon following its inflation during percutaneous coronary intervention (PCI) is an unusual complication. We report a case of an undeflatable stent balloon in a 70-year-old male, who underwent PCI for the right coronary artery after failed thrombolysis with streptokinase. After many failed attempts, the patient was cautiously managed by controlled puncture with a stiff guide wire. The procedure was successful without any hemodynamic compromise and ventricular tachycardia.
\end{abstract}

Keywords: angioplasty, balloon, complications, percutaneous coronary intervention, undeflatable stent balloon

\section{Introduction}

Percutaneous coronary intervention (PCI) is considered a mainstay invasive technique for treatment of coronary artery disease. However, it encounters few predictable as well as unpredictable complications. Although such complications occur in only $1 \%-2 \%$ of patients, they could be fatal and catastrophic [1]. We report a rare and unanticipated complication of an undeflatable stent balloon in a 70-year-old male, who underwent PCI for the right coronary artery (RCA).

\section{Case Report}

A 70-year-old male presented with persistent ST elevation in II, III, aVF, and RV4 had been admitted to our institute. Earlier, the patient had complained about chest pain and left shoulder pain and was diagnosed with acute coronary syndrome elsewhere. The patient had undergone thrombolysis with streptokinase. He had a history of ventricular tachycardia during transfer, which was reverted by cardioversion. The patient was then referred to our institute for further management and treatment. After clinical examinations, he was found to have acute inferior wall myocardial infarction (IWMI) and right ventricular myocardial infarction (RVMI) along with non-sustained ventricular tachycardia and cardiogenic shock. Coronary angiography revealed double vessel disease with totally occluded RCA from its proximal part (Fig. 1a) and $80 \%$ stenosis in the left anterior descending artery. A rescue angioplasty was planned. The ostium of RCA was wired with a Fielder FC (Asahi Corporation, Japan) guide wire and the lesion was predilated. Postballooning angiogram showed that RCA had a significant long lesion involving proximal and mid-distal regions, which required two stents. A $3 \times 32 \mathrm{~mm}$ Abluminus (Envision Scientific, India) drug-eluting stent (DES) was deployed in the mid-segment of RCA and was inflated at 10 atm for $15 \mathrm{~s}$ (Fig. 1b). After $15 \mathrm{~s}$, the balloon failed to deflate back (Fig. Ic). Various unsuccessful attempts were made to deflate the balloon. Initially, we tried to change the device. We also used saline instead of dye and later used two indeflators in three ways, but all the attempts were in vain. Later, we cut the distal hub of the balloon with the hope of balloon deflation, but it did not work. Finally, we intubated the catheter deeply and inserted a 0.014 " Miraclebros $6 \mathrm{~g}$ guide wire (Vascular Perspectives, UK) into the RCA (Fig. Id), placed it proximal to the balloon and punctured it. Ideally, these kinds of guide

This is an open-access article distributed under the terms of the Creative Commons Attribution-NonCommercial 4.0 International License, which permits unrestricted use, distribution, and reproduction in any medium for non-commercial purposes, provided the original author and source are credited, a link to the CC License is provided, and changes - if any - are indicated. 

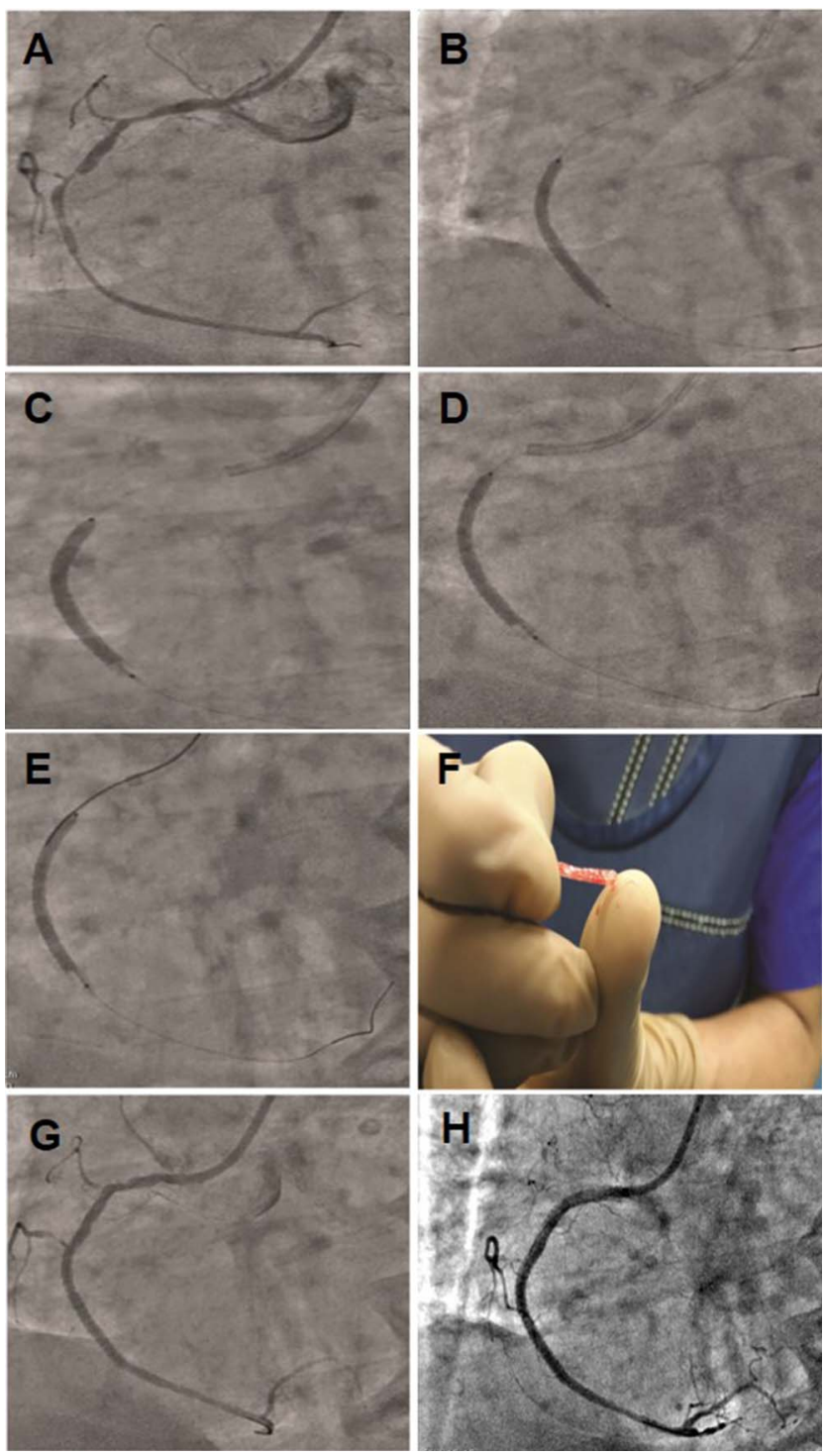

Fig. 1. (A) Angiographic view of stenosis in the mid RCA; (B) stent deployment in mid RCA (time 19:02); (C) failure to deflate the stent balloon (time 17:10); (D) negotiating a stiff guide wire; (E) balloon removal from the RCA; (F) balloon after removal from the RCA; $(\mathrm{G})$ final TIMI flow; and $(\mathrm{H})$ post-dilatation angiogram

wires are placed with a microcatheter, but we carried out the procedure with $6 \mathrm{~F}$ guide catheter via radial approach, so it was not possible. No dissection occurred. The balloon started to deflate, slackened, and lost its grip. Subsequently, the entire hardware along with the balloon was removed (Fig. Ie) and the punctured balloon was retrieved from the coronary tree (Fig. If). The vessel was rewired and its proximal portion was stented with a $3 \times 36 \mathrm{~mm}$ Abluminus (Envision Scientific) DES covering the ostium of RCA followed by post-dilatation with a noncompliant balloon. Good final TIMI flow was achieved
(Fig. Ig). Post-dilatation angiogram showed satisfactory stent dilation, with no residual stenosis and dissection (Fig. 1h). The procedure duration was $18 \mathrm{~min}$. The patient was discharged in a stable condition and is under regular follow-up.

\section{Discussion}

Balloon deflation failure may be due to the operator, manufacturer, or patient [1]. Technical barriers that may attribute to such a complication are mechanical obstruction, kinking in the shaft, closure of the lumen supplying fluid for balloon deflation, or blockage of the lumen with solid material such as foreign bodies or crystallized contrast [2]. All these obstacles prevent the passage of adequate negative pressure required for deflation of the balloon. The exact mechanism for this unexpected complication in our case could be due to any of the aboveexplained plausible reasons. In our case, we believe the proximal balloon weld, the place where the balloon was laser welded to catheter shaft, collapsed when the area toward the tip of the balloon was restrained while withdrawal when the catheter shaft had sufficient pulling force exerted on it.

The most common technique used to approach the dilemma of balloon deflation failure has been balloon inflation beyond maximal rated pressure to facilitate its bursting. This, however, does not guarantee that the balloon will burst and is instead accompanied by risks such as vessel rupture, balloon rupture, balloon or guide wire entrapment, slow or no blood flow, or fatal coronary perforation [3]. The second alternative suggested is intubation of the undeflatable balloon with either the anterior or posterior stiff end of either a $0.014^{\prime \prime}$ or $0.018^{\prime \prime}$ stiff guide wire. The stiff end of a $0.018^{\prime \prime}$ guide wire being much more radio opaque than the $0.014^{\prime \prime}$ wire can easily lead the catheter due to fluoroscopic properties. This could have attributed the success encountered with a $0.018^{\prime \prime}$ guide wire [3]. Our patient was a well-known case of acute IWMI along with RVMI and cardiogenic shock, so we preferred not to perform this technique.

Takama et al. [4] outlined various stepwise strategies that may be adopted by the operator when faced with the challenge of a non-deflatable balloon. The first step was application of negative suction pressure. The second step was transection of the balloon shaft. The third step was to pull out all system and the last option was to burst the balloon using a small guide catheter, either a $0.014^{\prime \prime}$ or $0.018^{\prime \prime}$ catheter. In our case, we initially attempted to change the entire device. We then replaced dye with normal saline and transected the distal hub of the balloon. All these techniques failed. Finally, we intubated the balloon with a 0.014 " catheter. The balloon lost grip and we were successful. 
In the case report demonstrated by Girish et al. [3], controlled puncture was preferred over uncontrolled rupture of balloon with high inflation pressure. Thus, when confronted with an unusual complication of non-deflatable stent balloon, the technique of balloon puncture with a stiffer guide wire can be applied, especially in patients with suitable coronary anatomy and hemodynamic compromise.

In 2004, Taxus (Boston Scientific Corp., Natick, MA, USA) stents were recalled due to increased incidences of balloon deflation failure. Investigations revealed a manufacturing defect leading to the collapse of the shaft of the balloon during negative suction by the indeflator [3]. Devices that have failed should not be discarded. Instead, causes for failure should be investigated by experts. Failure to identify and analyze these mishaps may invite further mishaps in the future.

\section{Conclusions}

Cardiologists should be prepared for complications such as balloon deflation failure during PCI procedure. In patients with hemodynamic compromise, technique of puncturing the balloon with a stiff guide wire should be considered and preferred. Moreover, a cath-lab should be equipped with the necessary devices to resolve all kinds of procedural complications and stand-by surgical back-up during PCI procedure should be maintained.

Funding sources: None.

Author's contribution: RT has performed the procedures and written the manuscript.

Conflict of interest: The author declares no conflict of interest.

\section{References}

1. Bostan M, Şatiroğlu Ö, Erdoğan T, Durakoğlugil ME, Uğurlu Y: A rare complication: Undeflatable balloon of the stent. Interv Med Appl Sci 5, 43-45 (2013)

2. Gilchrist IC: Troubleshooting and treating the balloon that fails to deflate. Catheter Cardiovasc Interv 77, 62 (2011)

3. Girish M, Gupta MD, Tyagi S: Entrapped coronary angioplasty stent balloon due to nondeflation: Percutaneous retrieval by a simple technique. Catheter Cardiovasc Interv 77, 58-61 (2011)

4. Takama T, Ito $\mathrm{Y}$, Ishimori H, Tsukahara R, Muramatsu T: Failure of a balloon to deflate during post dilatation in a coronary artery. Cardiovasc Interv Ther 30, 57-60 (2015) 